\title{
Mesothelioma: Hippo pathway as a target, lessons from COMMAND
}

\author{
Dean A. Fennell and Essa Y. Baitei
}

Mesothelioma is an incurable cancer caused by exposure to asbestos. Several countries have witnessed a growth in incidence of epidemic proportions over the last two decades, and approved treatment is limited to frontline chemotherapy [1]. The recently reported COMMAND trial [2] was a robustly designed, hypothesis-driven, double blind randomized phase II trial. This study evaluated the efficacy of the focal adhesion kinase inhibitor Defactinib versus placebo as a maintenance therapy in patients with Merlin negative mesothelioma [2]. COMMAND is one of the few reported randomized trials in mesothelioma that have incorporated prospective molecular stratification, another being the ADAM study [3].

COMMAND was negative, despite hopes of recapitulating preclinically observed synthetic lethality in the context of NF2 mutation [4], as well as targeting of the stem cell compartment [5]. Merlin is encoded by NF2 which undergoes positive selection in mesothelioma [6], a gene affected by somatic copy number alterations, fusions and epigenetic suppression [7]. In COMMAND, detection of aberrant Merlin, was therefore determined

using immunohistochemistry to minimize false negative stratification that could occur through exclusively genetic screening.

Since the initiation of the COMMAND trial, comprehensive genomic studies have revealed extensive genetic disruption of hippo signaling in mesothelioma involving multiple components of this tumor suppressor pathway $[7,8]$. In the Tumour Genome Atlas cohort for example, $51 \%$ of mesotheliomas harbour at least one somatic alteration in the Hippo pathway, with more than one aberration occurring in $19.5 \%$ (Figure 1). These genetic alterations involve, in addition to NF2, LATS2 (a positively selected gene), MST1, LATS1, SAV1, and RASSFA1, all capable of phenocopying loss of NF2summarized in figure $1[9,10]$. In hindsight, patient enrichment for just one of these components may have sampled only a proportion of "sensitive" phenotypes, limiting the ability to detect a signal.

A phase II window of opportunity trial involving defactinib monotherapy in patients prior to surgical resection demonstrated a promising $80 \%$ disease control

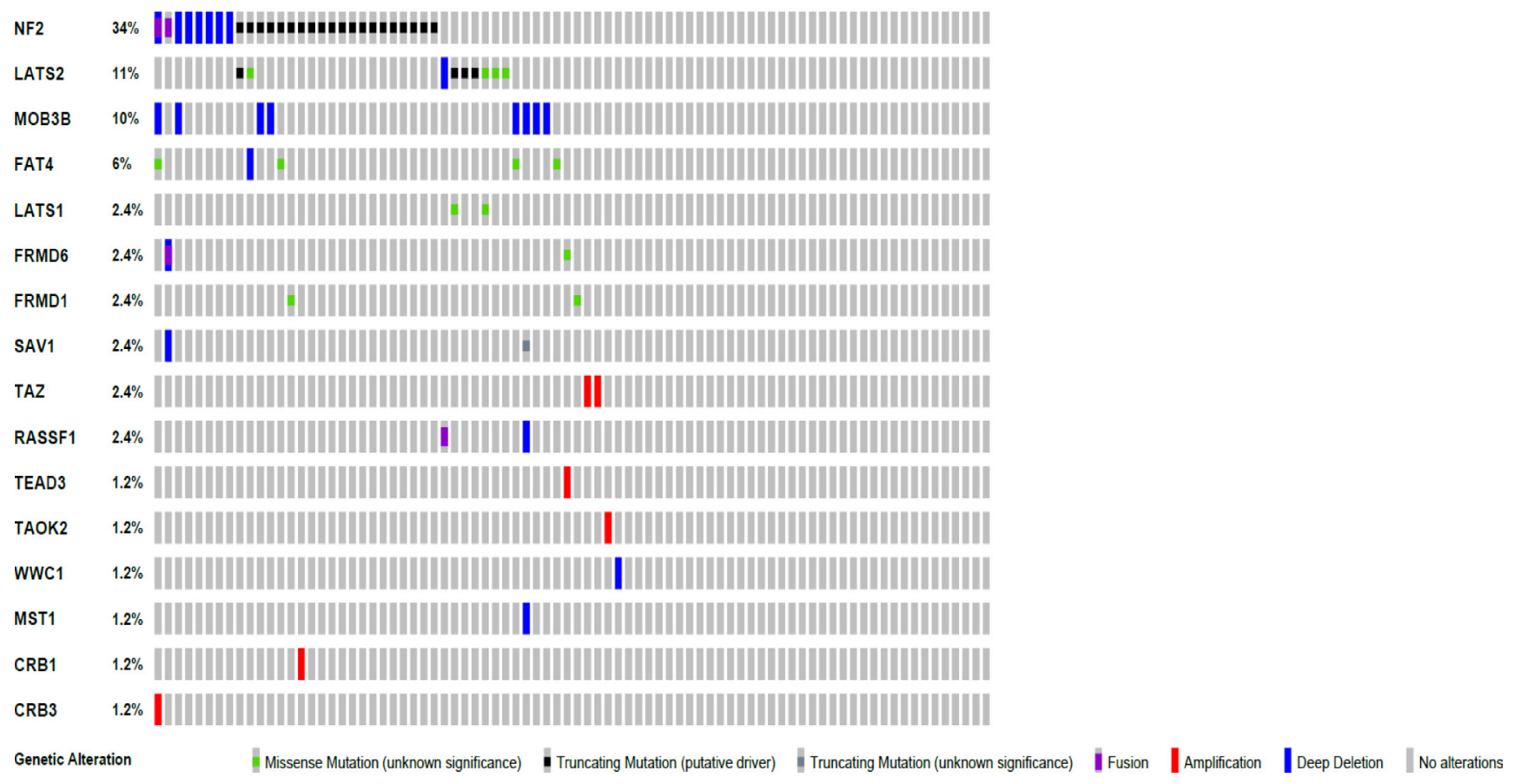

Figure 1: Heatmap summarizing hippo pathway mutations across 82 patients in the tumour genome atlas cohort $[8,15,16]$. 
and $13 \%$ response rate [11]. Interestingly, responses were not limited to Merlin-negative mesotheliomas. As the hippo pathway converges on YAP/TAZ-TEAD driven transcription [12], pharmacological disruption of the YAP/ TEAD complex could provide a strategy for targeting hippo defective mesothelioma irrespective of the specific pathway defect [13].

After the initiation of the COMMAND trial, another important insight into FAK biology came to light. FAK plays a crucial role in regulating the tumour microenvironment via augmentation of Treg abundance [14]. Inhibiting FAK drives a CD8 host response with evidence of reduced Tregs both preclinically and clinically $[11,14]$. This finding has been translated into a Cancer Research UK phase 1 clinical trial combining defactinib with pembrolizumab in patients with unselected, relapsed mesothelioma (NCT02758587).

In summary, targeting the Hippo pathway remains a potentially promising strategy for controlling mesothelioma. Widening the net to capture more hippo deficient phenotypes through the use of comprehensive hippo defective biomarkers, or directly antagonizing $\mathrm{YAP} / \mathrm{TEAD}$ transcription may provide next-generation approaches to phenocopying this important tumor suppressor pathway in mesothelioma.

\section{CONFLICTS OF INTEREST}

The authors declare no conflicts of interest. D.A.F is Advisor to Inventiva, Paredox Therapeutics.

\section{FUNDING}

D.A.F receives research funding and/or support from Astex Therapeutics, Bayer Oncology, Boehringer Ingelheim, Bristol Myers Squibb, Clovis Oncology, Eli Lilly, Roche Genentech, MSD, Bergen Bio, Atlas Biomed.

Dean A. Fennell: University of Leicester and University Hospitals of Leicester, Leicester Mesothelioma Research Programme, Leicester Cancer Research Centre, Leicester, Leicestershire, UK

Correspondence to: Dean A. Fennell, email: df132@le.ac.uk

Keywords: hippo pathway, focal adhesion kinase, mesothelioma, defactinib, NF2

Received: May 16, 2019

Published: June 18, 2019

\section{REFERENCES}

1. Vogelzang NJ, et al. J Clin Oncol. 2003; 21:2636-44. https://doi.org/10.1200/JCO.2003.11.136. [PubMed]

2. Fennell DA, et al. J Clin Oncol. 2019; 37:790-98. https:// doi.org/10.1200/JCO.2018.79.0543. [PubMed]

3. Szlosarek PW, et al. JAMA Oncol. 2017; 3:58-66. https:// doi.org/10.1001/jamaoncol.2016.3049. [PubMed]

4. Shapiro IM, et al. Sci Transl Med. 2014; 6:237ra68. https:// doi.org/10.1126/scitranslmed.3008639. [PubMed]

5. Kolev VN, et al. Oncotarget. 2017; 8:51733-47. https://doi. org/10.18632/oncotarget.18517. [PubMed]

6. Martincorena I, et al. Cell. 2017; 171:1029-1041.e21. https://doi.org/10.1016/j.cell.2017.09.042. [PubMed]

7. Bueno R, et al. Nat Genet. 2016; 48:407-16. https://doi. org/10.1038/ng.3520. [PubMed]

8. Hmeljak J, et al. Cancer Discov. 2018; 8:1548-65. https:// doi.org/10.1158/2159-8290.CD-18-0804. [PubMed]

9. Sekido Y. Pathol Int. 2011; 61:331-44. https://doi. org/10.1111/j.1440-1827.2011.02666.x. [PubMed]

10. Murakami H, et al. Cancer Res. 2011; 71:873-83. https:// doi.org/10.1158/0008-5472.CAN-10-2164. [PubMed]

11. Bueno R, et al. J Clin Oncol. 2017; 35:8555-8555. https:// doi.org/10.1200/JCO.2017.35.15 suppl.8555.

12. Zanconato F, et al. Cancer Cell. 2016; 29:783-803. https:// doi.org/10.1016/j.ccell.2016.05.005. [PubMed]

13. Liu-Chittenden Y, et al. Genes Dev. 2012; 26:1300-05. https://doi.org/10.1101/gad.192856.112. [PubMed]

14. Serrels A, et al. Cell. 2015; 163:160-73. https://doi. org/10.1016/j.cell.2015.09.001. [PubMed]

15. Gao J, et al. Sci Signal. 2013; 6:pl1. https://doi.org/10.1126/ scisignal.2004088. [PubMed]

16. Cerami E, et al. Cancer Discov. 2012; 2:401-04. https://doi. org/10.1158/2159-8290.CD-12-0095. [PubMed]

Copyright: Fennell et al. This is an open-access article distributed under the terms of the Creative Commons Attribution License 3.0 (CC BY 3.0), which permits unrestricted use, distribution, and reproduction in any medium, provided the original author and source are credited. 